This is a self-archived version of an original article. This version may differ from the original in pagination and typographic details.

Author(s): Lahti, Annukka

Title: Too much? Excessive sexual experiences in bisexual women's life stories

Year: 2018

Version: Accepted version (Final draft)

Copyright: @ 2017 , Macmillan Publishers Ltd., part of Springer Nature

Rights: In Copyright

Rights url: http://rightsstatements.org/page/lnC/1.0/?language=en

Please cite the original version:

Lahti, A. (2018). Too much? Excessive sexual experiences in bisexual women's life stories.

Subjectivity, 11(1), 21-39. https://doi.org/10.1057/s41286-017-0042-x 


\title{
Too much? Excessive sexual experiences in bisexual women's life stories
}

\author{
Abstract \\ This article explores bisexual women's sexual experiences at the edges of or between \\ relationships. It draws on the follow-up interviews of a longitudinal interview set conducted \\ in 2005 and 2014-2015 with bisexual women and their partners, who do not identify as \\ bisexuals. Bisexual women's spontaneous, detailed and affective narrations of sexual \\ experiences in the follow-up interviews caught the author's attention. Although the \\ experiences were often narrated as pleasurable, they could be overwhelming, and women also \\ expressed concern that they were excessive, “too much". The analysis of the women's \\ accounts utilizes and develops a psychosocial concept of excess. It reveals that the \\ excessiveness of the women's sexual experiences is constituted by bisexuality and \\ monogamy-related norms that restrict women's sexuality, and also by the non-rational \\ psychic dimensions of these experiences. Within the normative limits of feminine sexuality, \\ sexuality's excess often plays a propulsive role as the women strive to become sexual \\ subjects.
}

Keywords: sexuality, excess, women, bisexuality, psychosocial, relationships

\section{Introduction}

Marriage, cohabiting and gendered ways of being in relationships have become a matter of reflection and "choice" in contemporary Western societies following the individualization and democratization of intimate life (e.g. Adkins, 2002; Barker and Langdridge, 2010; Giddens, 1992; Roseneil, 2007). Yet many relationship-related hierarchies concerning gender 
and sexuality persist (Author, 2015; Magnusson, 2005; Farvid and Braun, 2013). A monogamous couple relationship is still regarded as the most respectable way of organizing intimate life (Barker and Langdridge, 2010; Farvid and Braun, 2013), and has been the central vehicle through which same-sex desire has gained social acceptance (Heaphy et al, 2013; Warner, 2000). The couple norm remains strong as family life and sociability are organized around couple relationships (DePaulo and Morris, 2005; Ketokivi, 2012).

Despite growing academic and public interest, non-monogamous ways of arranging intimate life remain marginalized (Barker and Langdridge, 2010; van Hooff, 2017). Yet there are ambivalences and tensions around contemporary monogamous couple relationships (Beck and Beck-Gernsheim, 1995; Perel, 2007; Shaw, 2013). Alongside the persistence of ideas about romantic love, 'the one' and the couple, people are expected to pursue their personal life goals and express their individual selfhood through sexuality (Barker and Langdridge, 2010; Beck and Beck-Gernsheim, 1995; Gill, 2008). This tension may have become particularly pronounced in a culture of 'romantic renaissance' (Kontula \& Mäkinen, 2009). Attitudes towards infidelity in relationships have become judgmental to an increasing extent since the turn of the millennium (Kontula \& Mäkinen, 2009; van Hooff, 2017).

These norms may have a particular effect on the lives of bisexual women, since bisexuality renders these tensions visible (Author, under review). In this article, bisexuality refers to the experience of sexual attraction to or desire for more than one gender ${ }^{\mathrm{i}}$ (Barker and Langdridge, 2008; Kangasvuo, 2014; Monro, 2015). In Western cultures, which emphasise the gendered body as an object choice of desire over other aspects of a person (Butler, 1990), the notion of bisexuality draws attention to the excess of sexuality beyond the cultural ideal of the dyadic relationship. It interrogates the normative ideal of one partner who meets all our emotional and sexual needs (Author, under review). People across sexuality and gender divides have to negotiate desires that exceed the monogamous ideal (Finn, 2012), yet 
bisexuality is persistently culturally associated with hypersexuality and promiscuity (Gustavson, 2009; Hayfield et al, 2014; Kangasvuo, 2014). Bisexual women thus engage in negotiations concerning sexual and relationship arrangements from a challenging cultural position, because relationship and sexuality related norms may have particularly stigmatizing effects on them (Author, under review, Klesse, 2005).

Despite the recent "sexualisation" of popular culture and an increase in queer content in Western contexts since the mid-1990s (Gill, 2008b; Karkulehto, 2011; Mistry, 2000), feminist scholars have addressed the difficulty of theorizing women's sexual subjectivity and desire on their own terms (Barker and Gill, 2012). Gill $(2007 ; 2008 \mathrm{a})$ has turned attention to mainstream culture's "post-feminist” tendency to represent women's sexuality as autonomous and empowering - although these representations often resemble older sexual scripts that posit women as the object of male fantasy (Barker and Gill, 2012; Kolehmainen, 2012). The limits of women's sexuality have been refined: women should be sexual in (preferably heterosexual) couple relationships, but not too sexual or sexual in the wrong way (Harvey and Gill, 2011; Moran and Lee, 2014). When women engage in casual sex it is often constructed as "not a natural act" (Farvid and Braun, 2013). Despite its frequent cultural representation, casual sex is often constructed as a transitory and incomplete sexual arrangement (Farvid and Braun, 2013). These constructions strengthen the status of sex in monogamous relationships as the most desirable sex (Farvid and Braun, 2013; Finn, 2012). This article analyses bisexual women's sexual experiences that are "too much" according to prevailing social norms regulating women's sexuality and monogamous relationships. To fully understand the excessive character of women's sexual experiences, it is necessary to bear in mind that sexuality is not only constrained by norms that dictate how women should be sexual (Harvey and Gill, 2011; Moran and Lee, 2014), but is also shaped by affective, non-rational psychic dimensions of relating (Johnson, 2015; Roseneil, 2006). This reflects the 
psychoanalytic notion of sexuality as something that unsettles the fantasy of a sovereign subject (Berlant and Edelman, 2014; Butler, 1991; Stein, 2008). Nonsovereignty refers to our inability to know ourselves entirely or to be fully in control of ourselves (Berlant and Edelman, 2014; Pirskanen, 2008; Woodward, 2015). This "prompts our misrecognition of our own motives and desires" (Berlant and Edelman, 2014, viii).

In order to get an enriched view of the complex meanings of sexual exploration in women's lives, I will incorporate contemporary psychoanalytic thinking about sexuality as excess into my analysis (Benjamin and Atlas, 2015; Stein, 2008). My aims are to 1) develop a psychosocial understanding of sexual excess so that it encompasses both sexuality-related norms and non-rational, unconscious psychic dimensions, and 2) show that without the concept of excess it is impossible to understand women's sexual experiences in the context of their relational and affective sexual life stories.

\section{Psychosocial exploration of sexuality's excess}

By adopting a psychoanalytic concept of excess, I seek to work with aspects of experience that are not consciously known or easily represented linguistically - often referred to as affect (Baraitser and Frosh, 2007; Blackman, 2010; Koivunen, 2010; Sedgwick, 2003). I follow such feminist and queer approaches to affect, which continue to formulate new questions about sexual subjectivities by utilising the critical potential of psychoanalytic thought (Berlant and Edelman, 2014; Gregg and Seigworth, 2010; Koivunen, 2010, 59). My approach to subjectivity, sexuality and affect is thus psychosocial (Baraitser and Frosh, 2007; Blackman et al, 2008; Johnson, 2015; Woodward, 2015).

Psychosocial research addresses the question of the relationship between the social and the psychic, which are seen as inextricably intertwined in psychosocial studies (Woodward, 2015, 5). It incorporates a psychoanalytic understanding of the unconscious (Woodward, 
2015,82 ), but also seeks to go beyond the universalism of psychoanalytic theory (Blackman et al, 2008; Lucey et al, 2003; Roseneil, 2007; Walkerdine, 2015). There has been heated debate about the nature of the relationship between "inner" and "outer" (Frosh and Baraitser, 2008; Johnson, 2015). My study draws on the notion that subjects and desires are formed in the intertwining of the "internal" psychic and "external" social, "always immersed in a flux that is neither inside nor out" (Frosh and Baraitser, 2008, 354; Pirskanen, 2008).

Psychoanalytical concepts, such as excess, are often useful for analysing this interweavement (Frosh \& Baraitser 2008).

In many poststructuralist theories, for example in Judith Butler's (psychosocial) performative theory of gender $(1990,1991)$, the notion of excess marks "the uncategorizable, the unsymbolizable, that which exceeds the regular frame imposed on it" (Stein, 2008, 48). For Butler $(1990,1991)$, sexuality is excessive in the sense that it can never be fully expressed in a gender presentation or narrative. With the concept of excess, Butler refers to psychic space that always "exceeds the domain of the conscious subject" (Butler, 1991, 315). However, this conceptualization alone does not explain why some sexual experiences are characterized by "too muchness" and "excess" (Benjamin and Atlas, 2015; Stein, 2008).

Ruth Stein (2008) suggests that contemporary psychoanalytic thinking is necessary in order to explore the excessive, shame-linked and transgressive aspects of sexuality. Contemporary psychoanalytic thinking about sexuality as excess is strongly influenced by Laplanche (1987, cited by Stein 2008; Benjamin and Atlas, 2015), who theorizes it in terms of the early overwhelming of the psyche (Benjamin and Atlas, 2015). The child is overwhelmed by the parent's excess - the parent is older and bigger, and the adult's unconscious messages about sexuality are too much for the child to contain in its psyche. Thus sexuality always begins with an unconscious communication from the (excessive) other (Laplanche 1987 cited by Benjamin and Atlas, 2015). 
Despite the universalizing tendencies of psychoanalytic theorizations of excess, Stein (2008) keeps the concept in motion by discussing it through different conceptualizations. She suggests that the various types of excess together constitute the compelling power of sexuality: "the overstepping of boundaries, the sense of overbrimming with inordinate arousal that makes one feel it cannot be encompassed" (Stein, 2008, 44). Her discussion of sexual experiences that can "sometimes be strange, excessive, 'perverse' and irrational" (Stein, $2008,45)$ does not pathologize these experiences, but rather comes close to Kalha's (2007, 27-28) queer reading of Freud (2000/1905), for whom all desire is more or less perverse. Not only does excess transgress regulatory frames, as in poststructuralist theories (Stein 2008, 50), but it can also transgress boundaries between self and other, and within oneself (Stein 2008, 63).

Therefore, in my psychosocial deployment of the concept of excess, I take seriously how social norms regulating bisexual women's sexuality may contribute to the 'feel' of 'too muchness' of women's sexual experiences. Yet, in order to gain an enriched view of the meanings of sexual exploration in women's lives, I have incorporated into my analysis psychoanalytic ideas of excess (Stein, 2008) as (1) an actively pursued shattering of structure (Bersani, 1995), (2) a way of dealing with our lonely, discontinuous being (Bataille 1957, 1976 cited by Stein 2008, 54-57), and (3) an (over)excitement that can turn from grace to abomination (Stein, 2008). By showing that these 'social' and 'psychic' aspects of excess cannot be easily separated, but are inextricably intertwined in women's accounts of their sexual experiences, the article offers a new, psychosocial understanding of sexual excess.

\section{Materials and methods}


The article draws on a study on bisexuality and relationships that incorporates a longitudinal set of interviews. I conducted seven original couple interviews with bisexual women and their partners in 2005, and individual follow-ups in 2014-2015. In the couple interviews, four of the bisexual women had female partners, two had male partners, and one woman's partner was a transman. None of the partners identified as bisexualii ${ }^{\mathrm{ii}}$. For the follow-up interviews I was able to reach 11 participants, six bisexual women and five (ex-) partners: two men and one woman, whose gender identities had stayed the same across both interview rounds. The ex-partner, who had identified as a transman in the couple interview, identified as a man in his follow-up interview. An ex-partner, who had identified as a woman at the first interview, said during the follow-up that their gender was "in the making”. I was unable to reach two partners of one female couple, whereas one former female partner of a bisexual woman did not want to participate while also refusing permission to use the 2005 couple interview in the study. This article mainly draws on the bisexual women's follow-up interviews of 2014 2015, while their ex-partners follow-up interviews and the five couple interviews serve as reference points for my analysis.

I conducted both sets of interviews in five Finnish cities, in the participants' homes or other locations that offered privacy. They were in-depth interviews that lasted between one and four hours. Interviews were audio-recorded and transcribed using a simplified version of Jefferson's (2004) system. At the time of the couple interviews, the participants were aged 22-42 (32-52 at the follow-up interviews). They were well educated: at the time of the follow-up interviews, eight participants had degrees, and three had vocational qualifications. I originally recruited the participants through a research request aimed at bisexual women and their partners. Four of the women who responded to the original interview request as bisexual women mostly still used bisexuality as an identity label in follow-up interviews; one woman identified as non-heterosexual, one woman did not label herself. The latter said that she 
strongly felt that she wanted to share her life with a man. However, she referred to many of her past and present (sexual) experiences as bisexual. Generally, bisexual identification entailed complex negotiations around sexuality and identity labels (see also Author, 2015; Author, under review). This highlights the queer theoretical notion that desire and desiring subjects cannot easily be put into clearly defined identity categories that will remain fixed for life (Butler, 1991; Giffney, 2009).

My study reflects Heaphy and Einarsdottir's (2013) finding that interviewing couples together and apart generates different kinds of interview talk. The couple interviews of 2005 were semi-structured interviews concentrating on the participants relationships. In the couple interviews relationship stories drawing on the ideal discourses of enduring relationship and romantic love were dominant: participants aspired to form a durable relationship with one person, possibly for the rest of their lives. One other-sex relationship was described as an agreed open relationship that had never been put into practice. The individual interviews gave more complex picture of participants' (past and current) relationships and highlighted women's bisexual experiences.

By the time of the follow-ups, most participants had separated and found new partners. One couple had stayed married. Two of the bisexual women were now in long-term relationships with men, three were married to men, and one was involved with men and women. Although the criterion for participation in the follow-up interviews was participation in the 2005 interviews, I did not want to set the former interview as the point of departure, preferring to leave it to the participants to judge the significance of that relationship within the entirety of their relational life. I began the follow-up interviews with an open-ended narrative question, adopting a focused version of (Wengraf, 2001) biographical narrative interview method. As a response to the open-ended question, the interviewees produced rich biographical accounts centred on their romantic and sexual relationships. 
Particularly in the follow-up interviews with four bisexual women, sexuality and sexual experimentation emerged spontaneously as a central theme. In addition to their relationship histories, the bisexual women gave affective and detailed accounts of their sexual experiences and sexual experimentation. Yet, one bisexual woman did not talk about such experiences. With some exceptions, the sexual experiences were not located in the bisexual women's longterm relationships, but rather at the edges of or between relationships. Although these sexual encounters were often experienced as very pleasurable, the women also expressed concern that they were excessive, "too much". Women felt that things had got out of control during these life stages, and they could not fully understand why.

The affectivity of the women's narrations "haunted" me, and I felt that I should try to understand why their experiences appeared excessive (Blackman 2015, 26). It was the "hot" concentration on sexuality, the gratitude, pleasure and affectivity some women attached to their sexual experiences, that had caught my attention ${ }^{\text {iii }}$. The notion of pleasure alone could not capture the complexity of these experiences (see for example Melzer, 2010). The ambivalence through which the sexual experiences were told led me to address the meaning and function of such sexual experiences to the bisexual women - without forgetting their pleasurable aspects.

My discovering of the contemporary psychoanalytic writing on sexual excess (Benjamin and Atlas, 2015; Stein, 2008) and the different conceptualizations through which Stein (2008) approaches it revealed the women's experiences in a new light. By deploying the various psychoanalytic concepts of excess in my analysis (Benjamin and Atlas, 2015; Stein, 2008), it became possible to discover the unconscious aspects of women's sexual experiences that could not be reduced to the effects of the norms restraining respectable (bisexual) female 
sexualities. Especially the ambivalent character of sexual excess, which can easily turn from grace to abomination (Stein, 2008, 48), resonated with women's experiences.

Yet, how to combine psychoanalytic thought with the understanding of intimate life as socially and discursively patterned? What can a scholar do to bring "the unthought" to the representational surface (Clough, 2013, 176)? While analysing my interview data I followed Sedgwick's (2003) suggestion that the non-representational - excessive, irrational, unconscious - does not provide access "beneath, behind and beyond", but rather is "parallel with" and "beside" (Koivunen, 2010, 50; Sedgwick, 2003). In my analysis this meant paying attention both to the interviewee's investments in certain discourses and identity categories, as well as taking into account affective and irrational aspects of experience that are not easily put into words (Woodward, 2015, 82): for example paying attention to affectively intensive moments, to the thickly narrated passages and opacity of the interviewees' talk.

The psychosocial analysis highlighted that the excessiveness of the women's experiences comprised various elements that could not be reduced to either 'psychic' or 'social' dimensions. In women's accounts, they were inextricably intertwined. The excessiveness of women's experiences came to the surface through reading of different aspects that came together in women's accounts (Blackman, 2015).

\section{Bisexual women's excessive sexual experiences at the edges of or between}

\section{relationships}

Now I will analyse bisexual women's accounts of sexual experiences that took place at the edges of or between long-term relationships. These differed from person to person, but there were common factors that could be said to constitute the excessiveness of the experiences. 
These factors were 1) bisexuality, which as a desire for more than one gender does not fit neatly into cultural understandings of couple relationships and 2) the monogamous norm, which paradoxically assigns special meaning to sexuality that exceeds relationship boundaries. The narration of "excessive" sexual experiences was also characterized by more psychoanalytic aspects that manifested as 3) thickness and opacity of the narration, 4) excessive pleasure, 5) excess as an actively pursued shattering of structure, 6) excess as a way of dealing with one's lonely, discontinuous being, and 7) excess that can turn from grace to abomination.

\section{Bisexuality}

In the 2005 couple interviews, women's bisexuality tended to disappear in normative relationship talk, in which the interviewees positioned their relationship as a female or as an other-sex relationship, or as a trans relationship, on the basis of their partner's gender (Author, 2015). The follow-up interviews also revealed that the sense of being bisexual could decline in the course of a long-term relationship. If bisexual women felt sexual attraction to someone whose gender was other than their partner's, they often resorted to homo/hetero and man/woman binaries in order to make sense of their desires (Author, under review). This paradoxically raised questions about their (bi)sexual identities. This implicated that it was not easy to gain 'a sense of being' as a bisexual person in a relationship (Author, 2015; Author, under review).

Cultural divisions affect the status of same-sex and other-sex relationships, and also shape differences in how responsibilities such as household chores and emotion work are shared (Brewster, 2016; Umberson et al, 2015). Little wonder, then, that women would ponder whether they should live their lives with a partner of a different gender from their current partner, or that they would want to explore those desires. For example, for Ella (all names are 
pseudonyms) the open relationship arrangement that she referred to in the follow-up interview as her period of "sexual exploration" was at first connected with her wish "to be with a woman at some point". The periods when women had sex that exceeded a couple commitment were often connected in some ways with their (precarious) bisexual desire, although this was not the most prominent aspect of these periods.

Casual or non-exclusive sex after a break-up, or during phases when a couple commitment is not fixed, is not somehow more typical of bisexuals. Yet an opportunity to have sexual experiences with people of different genders might have special meaning for bisexual people because of the precariousness of bisexual identity (Hemmings, 2002; Sears, 2014; Storr, 1999). Anna explained: "I wanted to explore, like what am I, am I bisexual now or what. After the long relationship I wasn't sure any more." Sexual experiences with people of different genders could strengthen women's bisexual identities.

Nonetheless, the women were quite hesitant to link their sexual experiences to bisexuality, even if they valued them highly. Negative stereotypes of bisexuality haunted their accounts (Blackman, 2015). Anna said: “[B]ut it's not like I needed to have sex with both genders that otherwise I would feel being somehow in need, it's not like that --- I don't feel like that I am that kind of hyper- --- hypersexual bisexual." In this way she seemed to balance her otherwise joyful tone in the interview - "I enjoy my sexuality and I feel like a sexual being" - against the stereotypes that mark bisexual sexuality as hypersexual and thus too much.

\section{Monogamous norm}

The phases when women had sex casually or outside a couple commitment required much more explaining than (taken-for-granted) sex in a relationship (see also Farvid and Braun, 2013). Jenny said: 
I was infatuated with and had a sexual relationship with [a man] --- right after we had bought the apartment [with my husband], it was maybe a bit like, I don't know what it was, when I think about it now. --- Like a really bad idea, but maybe it was some kind of a test that are we serious with Erik.

Conversely, in the couple interviews of 2005, the couples' sex lives were rarely discussed spontaneously. Sexuality was talked about in a casual and distancing manner, as a taken-forgranted part of a couple relationship. Affectivity was attached to only one couple's account of their sex life: the transcouple defended themselves against the cultural construction of nonheteronormative sex as lack (see Author 2015, 439-441).

Women's affective accounts of their sexual experiences in the follow-up interviews resembled Finnish sexual autobiographies from the 1990s: "each writer's current, long-term relationship frequently received little attention, whereas various parallel relationships that had occurred at different stages of the writers' lives were depicted in great detail and with feeling" (Kontula and Mäkinen, 2009, 149). Finn (2012) argues that maintaining the monogamous order means constantly fending off the chaotic excess outside it. Western cultures, which stress the importance of monogamous couple relationships and fidelity, paradoxically assign special meaning to sexuality that takes place outside a couple commitment, contributing to the experience of it as excessive (Finn, 2012).

\section{Thickness and opacity of the narration}

In what follows I will highlight the women's narration of their excessive sexual experiences, which is constituted not only by bisexuality and monogamy-related norms but also by the non-rational psychic dimensions of those experiences. Excessive sexual experiences were often connected to relationship break-ups - the often difficult and painful task of disengaging oneself from an existing attachment and moving towards something new. 
Thickness and opacity characterized women's accounts of their experiences "at the edges". A long period of time could be narrated in one breath. When women described these periods of life, they were often still puzzled about what had happened and why, many years later. This highlights the excessive nature of sexuality: the "reasons" behind a person's actions can remain hidden, from the person herself and from the researcher, although we can try to make sense of them afterwards. This resonates with the notion that sexuality unsettles the fantasy of a sovereign subject (Berlant and Edelman, 2014; Butler, 1991; Stein, 2008), and points to the fact that we often misrecognise our own motives and desires (Berlant and Edelman 2014, viii).

Excessive pleasure

Pleasure was often an essential feature of women's sexual experiences during life phases when they could put their sexuality into practice more "freely" than in (monogamous) relationships. They described this pleasure in hyperbolic terms. Ella explained: "[w]ith that woman, first off the sexuality was absolutely, super super wonderful.”

Before these pleasurable experiences the women (and their partners) had often struggled in their relationships in various ways, including sexually. Anna described her long-term relationship with Emma:

$[W]$ e were together for ten years, and there were times when we had good sex and times we didn't have sex at all --- I stayed faithful but now I regret it --- yet I don't think that our relationship failed because the sex had been bad, it was other things --the fights.

This relationship struggle might have added extra pleasure to her new experiences. She expressed gratitude for them: "I am so happy that I have had these experiences --- I have had 
this enormous luck that I have by chance bumped into these people [of different genders] with whom I have been able to form these kinds of interesting, mutual, different kinds of relationships." Women's gratitude for the pleasurable sexual encounters might reveal the scarcity of these kinds of experiences in their personal past or in their cultural expectations, as they were not taken for granted but rather as a sign of enormous luck (Barker and Gill, 2012).The phase when Anna was no longer bound to a relationship also provided an opportunity to explore aspects of sexuality that had caused her to feel shame in her former relationship:

I have learned to listen to my body in a different way and notice if I want something. Before, I have suppressed that kind of desire. --- Or like, I knew I have had that kind of fantasy, but I had never thought --- that I'd be in a situation where they can be put [into practice] safely and otherwise that you can tell them to someone without feeling that you should be ashamed. Yeah, there are parts of my sexuality that have been cleansed of shame, because of these new experiences I've had after the break-up.

However, she anticipated an end to these pleasurable encounters: "I'm not expecting this to go on forever." The implication was that it was a bit too much, after all, for a woman to have this much sex with different partners. Usually it was anticipated that the end would come when the women entered new long-term couple relationships. Interviewees would say playfully that monogamy was not the best option in the long run, but most of them nevertheless settled for it, because they felt non-monogamous ways of arranging relationships "would get too messy" (Author, under review ).

Excess as an actively pursued shattering of structure 
The (internalized) monogamous norm was only one factor that would bring a feeling of "toomuchness" to women's non-exclusive sexual experiences. There was often a tumultuous feel to the women' narration of these life periods. Ella describes this phase of her life:

[F]or many years we did not really have sex. And in that phase it was already somehow, like I wondered if I was asexual or that I couldn't be bothered --- At that point we started to discuss poly-or actually it was me who started to discuss the possibility of poly relationships or polyamory, and I guess it was me who decided that from now on our relationship will be like that. After all, it wasn't like a joint decision at all. It was like my husband just agreed to that --- Then I had a relationship with a woman, at the same time as I was with my husband. --- After that I moved into this other affair with a man --- at the same time as I was with my husband --- at that point our relationship [with my husband] started to be really over, and then I stated that I cannot stay in this relationship any more. It was very much my decision that that relationship ended. --- And after that I still had that relationship going on for some time with that [other] man --- I was so very infatuated with him ---

--- For him [the husband] it [the break-up] came as a surprise. In a way he was the only person for whom, who experienced it as coming out of the blue. --- For him the break-up was really horrible.

Ella's phase of sexual exploration took place within an agreed open relationship, and at first she enjoyed her new sexual experiences. Her repeated statement that this happened while she was with her husband is telling of her awareness of the monogamous norm. The thick narration of the three different relationships, and her repeated statement that they happened partly simultaneously and in quick succession, might also reveal a "too-muchness" in a 
relational sense.. She left her marriage, and sometime later she also ended the relationship with the other man.

It also becomes clear in Ella's narration that she had struggled in her marriage. Her thick account resonates with the psychoanalytic notion of excess as the active shattering of a structure in order to enable new (ego) structures to evolve. This shattering might provide an opportunity to move towards more advanced and integrated ego structures. Bersani's (1995, 100) reading of Freud interprets sexual excess as "an aptitude for the defeat of power by pleasure, the human subject's potential for a jouissance in which the subject is momentarily undone". Although these women's psychic structures are beyond the scope of my research, Bersani's (1995) notion can highlight why ending a relationship often requires some kind of disaster whose creation the person only becomes aware of afterwards.

Ella became only gradually aware that it was she who had "decided" that her marriage would be an open relationship, and that her husband just "agreed to that". At the end of the interview, she said with tears in her eyes that she never wanted to hurt anyone like that again. Looking back, she reflected: "I don't know if we built this, like a kind of fantasy, that he could play this game that we were still together although this other person has all these other things going on as well.” The excessiveness of that life stage was present in Ella's perplexed account of both of her own and her husband's motives in the situation, although she tried to make sense of them in hindsight.

Excess as way of dealing with our lonely, discontinuous being

None of the women experienced the phase of increased sexual activity as solely pleasurable. Krista described her relationship with her girlfriend in the 2005 couple interview as "the first healthy relationship I've had", and in the follow-up interview as "the first time in my life 
when I felt good. --- A kind of happiness and good feeling was present." After leaving this four-year relationship, she entered a tumultuous, even chaotic phase:

In a way the year between my ex-girlfriend and my current [male partner] has been the most active regarding sex. Like for a year I had this slave, tried that side and then there was a number of casual-but in way there were like, I have never had, one time only I have been with someone I hooked up with in a bar, had sex with a complete stranger. --- So the people who hung around at that time, they were all people I kind of knew. Some were taken, but it was like maybe it was like searching for oneself, searching. One was quite lost with oneself at that time. Just let go, didn't care about anything at all. I could keep my job though ((laughing)) because of my boss I guess. They were like really flexible. At that point I got these terrible panic attacks and all that interfered with work. --- Before I woke up to reality ((laughing a little)) like this is not my thing. --- There was this workmate who was like a fuck buddy, who was really the only, like one of my only friends, like we were friends and we still are, really good friends. But like then there were others... That was a tough year. Quite educational, like now I know what kind of life is not good for me. That's not the kind of life you'd want.

At this point her narration thickened, and a whole year of her life was blurted out in almost one breath. On the one hand she described that year as her most active sexually; on the other she pitted her story against the norms of respectable female sexuality. There is a defensiveness when she says that she is not into one-night stands, and when she obliquely admits that she had sex with people who were in relationships. As if to explain herself, she says "maybe it was like searching for oneself." It appears to have been a turbulent time: her drinking got out of control, she almost lost her job, and she had "terrible panic attacks". 
Despite various sexual encounters, her account of her workmate as "one of my only friends" reveals her as quite lonely. For her it was "a tough year".

She reflects in retrospect that this phase might have been connected to her break-up: "Maybe it was --- in a way one tried to forget that [the break-up] --- I don't know, but it was not that easy for me either.” This resonates with Bataille's notion of the erotic as way of dealing with our "discontinuous" state of loneliness (Stein, 2008, 55), which can be particularly palpable when one has recently disengaged oneself from an important attachment. This resonates with Laura 's account after an especially hard break-up when her partner had cheated on her only a few months after they had married: "When I was single after Ellen, I had a crush on everybody, I was interested in all ... like men. Not like seriously. But I saw every guy as a potential sex partner." The excess of crushes and sexual desire for men might have served Laura, when she tried to deal with the tremendous sense of betrayal and hurt, still palpably present in the low, sad tone of Laura's voice, when she talked about the events related to her break-up with Ellen many years ago.

\section{Excess that can turn from grace to abomination}

Krista closed her account of her tumultuous year with a moral tone: "That's not the kind of life you'd want." However, the meaning of this phase in her life does not reveal itself easily. She also enjoyed her sexual experiences:

But I don't, like I don't regret it. For example I visited one couple, and as an experience it was good. In a way I didn't do anything I didn't want to do, but then again, like there was this, we were two women and two men and one of them, or both I guess, were junkies more or less and --- you wouldn't even think of using a condom or anything --- like you wouldn't take any responsibility for the things you did to yourself. 
Here the twofold character of sexual excess, which can easily turn from grace to abomination (Stein, 2008, 48), is particularly pronounced. Stein $(2008,48)$ remarks that although there are often attempts to separate "good" excess, which carries meanings of generosity, grace and freedom, from the "bad" excess of licentiousness, abomination and "sin", this pendulum quality reveals how excess functions. The pendulum, and the leaning towards the immoderate end of excess, ultimately wore this interviewee out. After a while she disengaged herself from the people she hung out with during the sexually intensive year and moved to another part of town.

\section{Sexual excess embedded in women's affective sexual and relationship histories}

After the life phases when bisexual women had excessive sexual relationships at the edges of or between relationships, they usually returned (or wished to return) to long-term, committed monogamous relationships emphasized in Western societies (Barker \& Langdridge, 2010; Van Hooff, 2017). However, my analysis troubles the idea that the (transgressiveness of) bisexual women's sexual and relationship choices could solely be understood through taking positions in monogamous or non-monogamous relationship discourses. It is not possible to fully understand the meaning of sexually excessive life periods without placing them in the context of women's affective sexual and relationship histories. Excessive sexual experiences can be important in themselves, and can play a propulsive role in women's lives (see Bersani, 1995).

When we examine how Krista's life unfolds through different phases, ruptures and (dis)continuities, for example, the affective texture - the "canvas" where her intimacies take place - becomes tangible (see Clough, 2013, 177). Her experiences of crude gendered violence and threat in her first relationship with a man cannot be overlooked as shaping what 
intimacy means for her. But also, as she says later in the interview, she grew up with an alcoholic mother, "in an atmosphere where whenever you uttered your own point of view, you would get trashed". On this affective canvas, the seemingly arbitrary order of Krista's life events - a stable, happy female relationship followed by a sexually tumultuous and even self-destructive phase - has an unconscious logic, reflecting the opacity of the subject, not totally in control of itself (Berlant and Edelman, 2014; Stein, 2008). Later she started dating a man, which she describes in the follow-up interview as sexually very intense: "our sex life has functioned very well and right from the beginning, it's been you know, like insane ... I don't know anybody else with whom it had been like that." And yet the situation is complicated. "We fight against his alcoholism," Krista explains.

These ruptures, continuities and discontinuities highlight how women's biographies are formed by "psychic life structured by temporality and the history of desires and negations" (Koivunen, 2010, 41). Yet women's biographical narratives do not only reflect their singular life histories, but are entangled with the social positions available to women as sexual subjects. It is not a coincidence that within Western gendered (power) relations women had experienced domestic and sexual violence, suffered eating disorders, and neglected their own sexual desires and needs in order to please their partners, and their female relationships had been downplayed and discriminated against. Ella describes how she experienced sexuality when she was young: "I just wanted to be the right kind of [girl] --- please the other."

Yet for all women who told affective stories about sexual experiences "at the edges", sexual pleasure also had a central place in their lives at the time of the follow-up interviews. Ella laughed: “[W]hat I would like to do mostly is to dance and to have sex ((laughs)) that's like the most important thing." Ella's and Anna's depictions of their current sexual experiences were filled with pleasure: 
[M]y [current] male partner has a very different life history and he's had lots of sex and lots of partners and has had a sexually rich life --- I think that it has been a great gift for me to have someone so free and ready to enjoy beside me --- our sex has been very very wonderful right from the beginning. (Ella)

[I]n one event, we danced and all of a sudden I had this orgasmic, ecstatic feeling that my body is jiggling and wiggling --- an intense, strong experience of pleasure about my body which is full of energy and which jiggles. (Ella)

[T] he kind of chastity and nervousness of youth is washed away --- and now you notice that sexuality is quite fun and it's something you can play with, that you can be quite liberated with it. Like even at the same time when you have sex you can talk about it --- that's a new experience for me and also that I have had the courage to try sadomasochistic sex --- (Anna)

Within the normative limits of feminine sexuality, these women have striven (both consciously and unconsciously) to become sexual subjects who find and own their desires (which of course is never fully possible). I have come to think of sexuality's excess not just as a power that might help us to transgress regulatory frames, but as energy that might allow (psychic) change (see Berlant and Edelman, 2014, viii; Bersani, 1995) - not necessarily dramatic or permanent change, but an energy for change that comes about as women's lives unfold.

\section{Conclusions}

In this article, I have explored the excessive character of bisexual women's sexual experiences at the edges of or between relationships. My analysis develops the psychosocial 
concept of excess, highlighting both the discursive regulation that constitutes women's experiences as excessive and the irrational, unconscious psychic dimensions of that excess. The excessiveness of these experiences is constituted by two cultural discursive factors. The first factor is women's bisexuality, which as a desire for more than one gender does not fit neatly into cultural understandings of couple relationships. If a woman feels sexual attraction to someone whose gender is other than her partner's during a relationship, it often paradoxically raises questions about her (bi)sexual identity (Lahti, 2018). Sexual experiences "at the edges" give women an opportunity to explore their sexuality and sexual identities anew. Yet even more prominent was the second factor: the monogamous norm in Western cultures, which stresses the importance of couple relationships and fidelity. Paradoxically it also assigns special meaning to sexuality that takes place outside a couple commitment, contributing to the experience of it as excessive from a moral point of view; a sentiment still applied more harshly to women than men (van Hooff, 2017). This was evident in the various explanations the women gave of the life phases during which they had sex with different partners. However, the life phases when women could explore their sexuality beyond a monogamous couple commitment could be experienced as very pleasurable. This was tangible in the affectivity and gratitude with which the bisexual women talked about their sexual experiences.However, the psychosocial analysis of women's sexual experiences highlighted the pendulum quality of sexual excess, which could easily turn from (over)excitement and grace to abomination (Stein, 2008). Women could feel that what happened was "too much" for them or that things got out of control. There were also other non-rational psychic dimensions of sexual excess present in the women's tumultuous life phases, as the sexual excess often seemed to carry a function of an "actively" pursued shattering of structure (Bersani, 1995); or a way of dealing with one's lonely, discontinuous being (Bataille 1957, 1976 cited by Stein 2008, 54-57) after a painful break-up. 
After phases of experimental sexual experiences "at the edges", the women usually returned (or wished to return) to long-term committed relationships. The non-monogamous ideas they contemplated in the interviews were often abandoned as unrealizable in the 'real world', reflecting the limited choices available for people living conventional (heterosexual) lives (Lahti, 2018; Barker, 2013; van Hooff, 2017). Yet, my analysis opens up a new way of thinking about the transgressiveness of bisexual women's sexual and relationships choices beyond simply taking positions in monogamous or non-monogamous relationship discourses.

My analysis shows that (transgressiveness) of bisexual women's sexual experiences cannot be separated from gendered power relations in Western societies. Women's affective sexual and relationship histories did not only reflect their singular life experiences, but also the social positions available to women as sexual subjects, often meaning limited options to explore sexuality or pleasure on their own terms. For bisexual women excessive sexual experiences were part of their ongoing identity work and perhaps necessary in order to transgress the deeply intertwined personal, interpersonal and cultural boundaries, which regulate (bisexual) women's sexuality and relationship behaviours. Excessive sexual experiences often played a propulsive role in the women's lives and brought them nearer to what they found sexually pleasurable. Sexual pleasure held a central place in the current couple relationships of all the bisexual women who had told affective stories about sexual experiences "at the edges". Sexuality's excess thus has the potential to complicate women's relationship with norms that dictate how they should be sexual. 


\section{References}

Adkins, L. (2002) Revisions: Gender and Sexuality in Late Modernity. Philadelphia: Open University.

Baraitser, L. and Frosh, S. (2007) Affect and encounter in psychoanalysis. Critical Psychology 21: 76-93.

Barker, M. and Gill, R. (2012) Sexual subjectification and Bitchy Jones's Diary. Psychology \& Sexuality 3(1): 26-40.

Barker, M. and Langdridge, D. (2008) II. Bisexuality: Working with a silenced sexuality. Feminism \& Psychology 18(3): 389-394.

Barker, M. and Langdridge, D. (2010) Whatever happened to non-monogamies? Critical reflections on recent research and theory. Sexualities 13(6): 748-772.

Bataille, G. (1957) Erotism: Death and Sensuality. San Francisco: City Lights Books.

Bataille, G. (1976) The Accursed Share. An Essay on General Economics: Vol. 2. The history of Eroticism. New York: Zone Books.

Beck, U. and Beck-Gernsheim, E. (1995) The Normal Chaos of Love. Cambridge: Polity Press.

Benjamin, J. and Atlas, G. (2015) The 'too muchness' of excitement: Sexuality in light of excess, attachment and affect regulation. International Journal of Psychoanalysis 96(1): 3963.

Berlant, L.G. and Edelman, L. (2014) Sex, or the Unbearable. Durham, North Carolina: Duke University Press. 
Bersani, L. (1995) Homos. Cambridge, Mass: Harvard University Press.

Blackman, L. (2010) Embodying affect: Voice-hearing, telepathy, suggestion and modelling the non-conscious. Body \& Society 16(1): 163-192.

Blackman, L. (2015) Researching affect and embodied hauntologies: Exploring an analytics of experimentation. In: B.T. Knudsen and C. Stage (eds) Affective Methodologies:

Developing Cultural Research Strategies for the Study of Affect. Basingstoke and New York: Palgrave Macmillan, pp. 25-44.

Blackman, L., Cromby, J., Hook, D., Papadopoulos, D. and Walkerdine, V. (2008) Creating subjectivities. Subjectivity 22: 1-27.

Brewster, M.E. (2016) Lesbian women and household labor division: A systematic review of scholarly research from 2000 to 2015. Journal of Lesbian Studies, online publication 3 September, doi: 10.1080/10894160.2016.1142350.

Butler, J. (1990) Gender Trouble: Feminism and the Subversion of Identity. New York: Routledge.

Butler, J. (1991) Imitation and gender insubordination. In: D. Fuss (ed.) Inside/Out: Lesbian Theories, Gay Theories. New York: Routledge, pp. 13-31.

Clough, P.T. (2013) Intimacy, lateral relationships and biopolitical governance. In: A. Frank, P.T. Clough and S. Seidman (eds) Intimacies: A New World of Relational Life. London and New York: Routledge, pp. 165-180.

DePaulo, B.M. and Morris, W.L. (2005) TARGET ARTICLE: Singles in society and in science. Psychological Inquiry 16(2-3): 57-83.

Eisner, S. (2013) BI. Notes for a bisexual revolution. Berkeley, California: Seal Press. 
Farvid, P. and Braun, V. (2013) Casual sex as "not a natural act" and other regimes of truth about heterosexuality. Feminism \& Psychology 23(3): 359-378.

Finn, M. (2012) Monogamous order and the avoidance of chaotic excess. Psychology \& Sexuality 3(2): 123-136.

Firestein, B.A. (ed.) (1996) Bisexuality: The psychology and politics of an invisible minority. London: Sage.

Foucault, M. (1981) The History of Sexuality: Vol. 1. Harmondsworth: Penguin.

Freud, S. (2000/1905) Three Essays on the Theory of Sexuality. New York: Basic Books.

Frosh, S.S. and Baraitser, L.L. (2008) Psychoanalysis and psychosocial studies.

Psychoanalysis, Culture \& Society 13(4): 346-365.

Giddens, A. (1992) The Transformation of Intimacy: Sexuality, Love and Eroticism in Modern Societies. Cambridge: Polity Press.

Giffney, N. (2009) Introduction: the 'q' word. In: N. Giffney and M. O’Rourke (eds) The Ashgate Research Companion to Queer Theory. Burlington: Ashgate, pp. 1-13.

Gill, R. (2007) Postfeminist media culture: Elements of a sensibility. European Journal of Cultural Studies 10(2): 147-166.

Gill, R. (2008a). Culture and subjectivity in neoliberal and postfeminist times. Subjectivity, 25(1): 432-445.

Gill, R. (2008b). Empowerment/sexism: figuring female sexual agency in contemporary advertising. Feminism \& Psychology, 18(1): 35-60. 
Gregg, M. and Seigworth, G. J. (eds.). (2010). The Affect theory reader. Durham N.C.: Duke University Press.

Gustavson, M. (2009) Bisexuals in relationships: Uncoupling intimacy from gender ontology. Journal of Bisexuality 9(3-4): 407-429.

Harvey, L. and Gill, R. (2011) Spicing it up: Sexual entrepreneurs and The Sex Inspectors. In: Gill, R. and Scharff, C. (eds) New Femininities: Postfeminism, Neoliberalism and Subjectivity. Basingstoke: Palgrave Macmillan, pp. 52-67.

Hayfield, N., Clarke, V. and Halliwell, E. (2014) Bisexual women's understandings of social marginalisation: 'The heterosexuals don't understand us but nor do the lesbians'. Feminism \& Psychology 24(3): 352-372.

Heaphy, B. and Einarsdottir, A. (2013) Scripting civil partnerships: Interviewing couples together and apart. Qualitative Research 13(1): 53-70.

Heaphy, B., Smart, C. and Einarsdottir, A. (2013) Same Sex Marriages: New Generations, New Relationships. Basingstoke: Palgrave Macmillan.

Hemmings, C. (2002) Bisexual Spaces: A Geography of Sexuality and Gender. New York: Routledge.

Jefferson, G. (2004) Glossary of transcript symbols with an introduction. In: G.H. Lerner (ed.) Conversation Analysis: Studies from the First Generation. Philadelphia: John Benjamins Publishing, pp. 13-31.

Johnson, K. (2015) Sexuality: A Psychosocial Manifesto. Cambridge: Polity Press. Kalha, H. (2007) Pornografia halun ja torjunnan kulttuurissa [Pornography in the culture of desire and repression]. In: H. Kalha (ed.) Pornoakatemia! Turku: Eetos, pp. 11-76. 
Kangasvuo, J. (2014) Suomalainen biseksuaalisuus: Käsitteen ja kokemuksen kulttuuriset ehdot. Oulu: Acta Universitatis Ouluensis: Series B, Humaniora 121.

Karkulehto, S. (2011) Seksin Mediamarkkinat. Helsinki: Gaudeamus.

Ketokivi, K. (2012) The intimate couple, family and the relational organization of close relationships. Sociology 46(3): 473-489.

Klesse, C. (2005) Bisexual women, non-monogamy and differentialist anti-promiscuity discourses. Sexualities 8(4): 445-464.

Koivunen, A. (2010) Yes we can? The promises of affect for queer scholarship. Lambda Nordica 15(3-4): 40-64.

Kontula, O. and Mäkinen, M. (2009) Between Sexual Desire and Reality: The Evolution of Sex in Finland. Helsinki: Population Research Institute, Family Federation of Finland.

Kolehmainen, M. (2012) Managed makeovers? Gendered and sexualized subjectivities in postfeminist media culture. Subjectivity 5(2): 180-199.

Lahti, A. (2015). Similar and equal relationships? Negotiating bisexuality in an enduring relationship. Feminism \& Psychology, 25(4), 431-448. doi:10.1177/0959353515574786

Lahti, A. (2018). Bisexual desires for more than one gender as a challenge to normative relationship ideals. Psychology \& Sexuality, 9(2), 132-147.

Laplanche, J. (1987) New Foundations for Psychoanalysis, Macey, D. (trans1.) 1989. Oxford: Blackwell. 
Lucey, H., Melody, J. and Walkerdine, V. (2003) Uneasy hybrids: Psychosocial aspects of becoming educationally successful for working-class young women. Gender and Education 15(3): 285-299.

MacLure, M. (2013) Classification or wonder? Coding as an analytic practice in qualitative research. In: R. Coleman and J. Ringrose (eds) Deleuze and Research Methodologies. Edinburgh: Edinburgh University Press, pp. 164-183.

Magnusson, E. (2005) Gendering or equality in the lives of Nordic heterosexual couples with children: No well-paved avenues yet. NORA: Nordic Journal of Feminist and Gender Research 13(3): 153-163.

McLean, K. (2004) Negotiating (non)monogamy. Journal of Bisexuality 4(1-2): 83-97.

Mistry, R. (2000). From "Heart and Home" to a Queer Chic: A Critical Analysis of Progressive Depictions of Gender in Advertising. Retrieved from http://www.theory.org.uk/mistry.htm [25.11.2017].

Melzer, P. (2010). 'And How Many Souls Do You Have?': Technologies of Perverse Desire and Queer Sex in Science Fiction Erotica. In: W. Pearson, V. Hollinger, \& J. Gordon (eds.), Queer Universes: Sexualities in Science Fiction. Liverpool University Press, pp. 161179.Monro, S. (2015) Bisexuality: Identities, Politics, and Theories. Basingstoke: Palgrave Macmillan.

Moran, C. and Lee, C. (2014) Women's constructions of heterosexual non-romantic sex and the implications for sexual health. Psychology \& Sexuality 5(2): 161-182.

Perel, E. (2007) Mating in Captivity: Unlocking Erotic Intelligence. New York: Harper. 
Pirskanen, J. (2008) The Other and the Real: How does Judith Butler's theorizing of the subject and contingency differ from the new Lacanian thought? SQS Journal 3(1): 1-14.

Ringrose, J. and Renold, E. (2014) "F**k rape!": Exploring affective intensities in a feminist research assemblage. Qualitative Inquiry 20(6): 772-780.

Roseneil, S. (2006) The ambivalences of Angel's "arrangement”: A psychosocial lens on the contemporary condition of personal life. Sociological Review 54(4): 847-869.

Roseneil, S. (2007) Queer individualization: The transformation of personal life in the early 21st century. NORA: Nordic Journal of Women's Studies 15(2): 84-99.

Sears, J.T. (2014) Becoming and being: Bisexuality and the search for self. Journal of Bisexuality 14(1): 3-6.

Sedgwick, E.K. (2003) Touching Feeling: Affect, Pedagogy, Performativity. Durham: Duke University Press.

Shaw, D. (2013) Intimacy and ambivalence. In: A. Frank, P.T. Clough and S. Seidman (eds) Intimacies: A New World of Relational Life. London: Routledge, pp. 98-114.

Stein, R. (2008) The otherness of sexuality: Excess. Journal of the American Psychoanalytic Association 56(1): 43-71.

Storr, M. (1999) Bisexuality: A Critical Reader. London and New York: Routledge.

Umberson, D., Thomeer, M.B. and Lodge, A.C. (2015) Intimacy and emotion work in lesbian, gay, and heterosexual relationships. Journal of Marriage and Family 77(2): 542-556.

van Hooff, J. (2017) An everyday affair: Deciphering the sociological significance of women's attitudes towards infidelity. Sociological Review, first published online 1 February 2017. 
Walkerdine, V. (2015) Transmitting class across generations. Theory \& Psychology 25(2):

$167-183$.

Warner, M. (2000) The Trouble with Normal: Sex, Politics, and the Ethics of Queer Life.

Cambridge: Harvard University Press.

Woodward, K. (2015) Psychosocial Studies: An Introduction. London and New York:

Routledge.

Word count: 8767 words

\footnotetext{
i Sometimes my use of the term bisexuality is questioned and other terms such as pansexuality, sexual fluidity or queer are suggested instead as they are thought to be more inclusive and convey attraction to more than two genders. Bisexuality, because it has bi in it, literally two, is thought to refer to a two-gender structure (Eisner, 2013, 49). However, the usage of the term bisexuality has developed in concordance with the development of queer theory of gender. In the current academic discussion, and already in one of the earliest interdisciplinary collections on bisexuality, bisexuality was defined as an attraction to more than one gender (Firestein, 1996). I do not see bisexuality and pansexuality as opposed to one another, but rather at least partly overlapping terms. Yet, often bisexuality is a more commonly known concept than pansexuality, which is the reason why I chose to use it in this research. Furthermore, participants of this research were originally recruited to the couple interviews in 2005 through a research request aimed at bisexual women and their partners.

ii While most partners reported similar sexual identities in both interviews, there were some fluctuations. Bisexual women's cis and trans male partners all identified as heterosexual in both interview rounds. Female partners often did not label themselves, but implied that they were lesbians rather than bisexuals. One who did not label herself at all in the couple interview identified strongly as a lesbian in the follow-up interview. One former female partner said in the follow-up interview that she was now also attracted to men.

iii In psychoanalytic literature, affective intensity is seen as a signal of where to look for important material (Baraitser \& Frosh, 2007). Coming from a different theoretical framework, from Deleuzo-Guattarian thought, Maggie MacLure (2013) suggests that affective intensities, which refuse to settle to decisive meanings, can be treated as glowing data hotspots also in qualitative research (Ringrose and Renold, 2014). Encouraged by these scholars I chose to concentrate on these sexual hot spots in my analysis.
} 